\title{
Juicio a un psicoanalista
}

\author{
Cristina Palomar Verea \\ doi: http://dx.doi.org/10.32870/espiral.v25i72.6954.g6076
}

De repente [en esa búsqueda] se revelan cosas que uno no quiere ver, no quiere saber. [Esos objetos] producen un efecto conmovedor, pero al mismo tiempo horrible. Por sí mismas, las cosas no significan nada, como los utensilios de cocina de una civilización antigua; pero sin embargo nos dicen algo, siguen allí no como simples objetos, sino como vestigios de pensamientos, de conciencia; emblemas de la soledad en que un hombre toma las decisiones sobre su propia vida. Paul Auster (1994, p. 19)

Sólo la máquina es transparente. B.C. Han (2013, p. 14)

Lo que digo es que, cuando el pasado no nos gusta, tendemos a esconderlo o ignorarlo o maquillarlo; lo que digo

es que la verdad no nos gusta: nos gustan las mentiras. Nos gusta pensar que Hitler era un monstruo inhumano, casi diabólico, que nada tenía que ver con nosotros ni con nuestros líderes, y que, si lo conociéramos, nos repelería; nos disgusta pensar que era como nosotros, que sedujo a gente como nosotros y que, por tanto, podría seducirnos. Esta ceguera -este rechazo a afrontar la realidad- nos deja inermes, del todo vulnerables a la fascinación épica y el idealismo sentimental y embustero de los periódicos e infatigables vendedores de paraísos que, como en cualquier época, viven en la nuestra. Están ahí, y nos encantan. Javier Cercas $(2015$, p. 8)

Sabemos que en el trabajo de investigación en ciencias sociales hablar o escribir sobre otros muchas veces es propio de los relatos que tienen como función la exhibición, reafirmación o producción de la identidad del narrador, así como el trazo de fronteras morales claras entre la posición subjetiva de

Fernando M. González (20 I 5). Igor A. Caruso. Nazismo y eutanasia. México: Tusquets. 
quien relata y de esos otros que son puestos en posiciones distintas o incluso antagónicas a las propias.

Esa distribución de posiciones, en el contexto de la elaboración de un texto, representa el trazo de los límites del sí mismo al producir al otro que, en su diferencia, confirma dichos límites por negación o contraste.

Por lo tanto, escribir relatos muchas veces habla más del narrador que de lo narrado, porque al construir en la narración un objeto preciso se ponen en juego los valores culturales, los significados y las vivencias personales de quien escribe, además de expresarse y personificarse los juegos de poder, las identidades y otros elementos subjetivos que lo implican. Por otra parte, es sabido que para construir las narraciones se producen datos que son procesados, seleccionados y puestos en escena para un público determinado y con objetivos específicos, que se tornan operativos sobre todo cuando dichos datos se buscan con técnicas acordes con dichos objetivos y de acuerdo con el público imaginado. Estos elementos sugieren líneas de análisis particulares de la información y una cierta organización del texto.

Es obvio, entonces, que tales narrativas no ocurren naturalmente, sino que son parte de un conjunto de mecanismos que no pueden separarse del contexto de su producción ni de la implicación de quien articula la narrativa en el objeto que se construye ni del público al cual esta última va dirigida (Coffey y Atkinson, 2003). Estos elementos están presentes en el libro titulado Igor A. Caruso. Nazismo y eutanasia, firmado por Fernando M. González (FG).

Este libro se trata de una obra compleja tanto por su estructura como por el tema que aborda, así como por la lógica argumentativa de su desarrollo y la calidad de su escritura. Para empezar, se trata de un texto múltiple, aunque en la portada del libro solamente está el nombre de FG como autor. Empieza con unas palabras preliminares de Alejandra de la Garza, presidenta del Círculo Psicoanalista 
Mexicano (CPM). Luego se incluye el documento central de FG (prólogo, introducción, doce capítulos, un epílogo y una reflexión final, en un total de ciento ochenta páginas de un libro de cuatrocientas una). Después se incluye un amplio cuerpo compuesto de otros textos, bajo el subtítulo de "Algunas miradas de miembros del CPM", que incluye tres trabajos: uno de Katia Weissberg Glazman, otro de Claudia Brinkop, y el último de Eloísa B. Rodríguez e Iglesias. Al final, se incluyen cuatro anexos, numerosas notas y la bibliografía de referencia.

¿A qué responde esta estructura multitextual cobijada bajo un solo nombre: a la necesidad de construir contrafuertes para sostener el texto central, o a la de distribuir la carga para proteger una sola firma detrás del esfuerzo colectivo? ¿O tal vez a la conciencia de la fragilidad de lo construido? Desde que se percibe esto, los lectores quedamos advertidos de que el libro que tenemos entre las manos requiere, al parecer, de mucho apoyo. Se desliza así en el lector la primera sensación de estar frente a un contencioso, en muchos sentidos.

El tema del libro tiene como trasfondo más general la línea de trabajo alrededor del vínculo de ciertos intelectuales con el nacionalsocialismo. Dicha línea no es nada nueva. De hecho, podría decirse que hay una producción bastante extensa de obras que han buscado denunciar no solamente la participación de algunos de estos intelectuales con el régimen nazi, sino también mostrar los elementos del trabajo de estos que se relacionan con el pensamiento de dicho régimen. Como Schmitt, Jünger y Heidegger (González Íñiguez, 1999; Faye, 2009), seguidos por Gadamer (Orozco, 1995), pasando por Wagner, Nietszche y Weber (García Olea, 2005) y llegando hasta Le Corbusier (De Jarcy, 2015), entre otros, muchos filósofos, académicos, escritores y artistas han sido puestos bajo sospecha de haberse vinculado con el nazismo de alguna manera, y se han buscado en sus obras los signos 
de ese vínculo funesto. También en el campo psicoanalítico se ha señalado ya a algunos de esos colaboradores con los nazis, entre otros a Jung (Ibarra, 1999; Hernández Lomelí, 1999), y ahora a Igor A. Caruso. ${ }^{1}$

¿Qué significa ese esfuerzo incesante de indagación y denuncia de la marca nazi en distintos sujetos y sus obras, que se origina en diferentes lugares y momentos? ¿De qué habla este esfuerzo y qué es lo que se busca con él? ¿Dicha marca representa el símbolo del mal, de la maldad más radical que se pretende situar en ciertos sujetos para salvar a los demás? El epígrafe de esta reseña, tomado de un artículo de Javier Cercas, habla de este tema, y resulta imposible no recordar el debate generado a partir de la publicación del libro de Hanna Arendt titulado Eichmann en Jerusalen, así como las críticas que Berlin y Below -entre otros- hicieron a la autora por haber planteado que Eichmann no era un monstruo, sino un ser humano corriente.

Pues bien, el libro de FG forma parte de esta compleja línea de trabajo. ¿Qué es lo que ha llevado, en el 2015, a un académico mexicano a interesarse en escribir un libro para denunciar la presencia de la marca nazi en un psicoanalista vienés que tuvo algunos vínculos con el proceso de institucionalización del psicoanálisis en México? ¿Qué significatividad $^{2}$ tiene este trabajo en el contexto espaciotemporal donde aparece?

I. Igor A. Caruso (1914-198I), psicoanalista austriaco de origen ruso que participó en la fundación de la primera organización freudiana internacional, autor de $L a$ separación de los amantes (1969), Psicoanálisis, marxismo y utopía (1974) y Narcisismo y socialización (1979) (todos publicados en México por Siglo XXI Editores), y que tuvo vínculos con algunos psicoanalistas mexicanos que participaron en la fundación del CPM, a finales de los años setenta.

2. En el campo de la reflexión metodológica, hablamos de significatividad para referirnos a aquello que habla de la importancia de un problema de investigación en términos del avance del conocimiento que propone o de su posibilidad para explicar algo, así como de su potencial para impedir mayores costes sociales en caso de no lograrlo. 
FG hace una indagación para establecer la actuación de Caruso durante la Segunda Guerra mundial y la ocupación nazi en Austria, a través de investigación documental y de entrevistas. Dichas pesquisas tienen como punto de partida la información encontrada por Cynthia del Castillo (en varios momentos del libro, el autor insiste despectivamente en que la encontró gracias a un teclazo en Wikipedia) que, a su vez, procedía de los trabajos de Evelyn List en Viena. En textos aparecidos previamente (los de List, pero también de Fallend y de otros autores que FG retoma para su libro), ya se había hablado de las actividades de Caruso en la Viena de los nazis.

También anteceden al libro de FG los artículos de la propia Cynthia del Castillo y de Rodolfo Álvarez del Castillo, publicados en internet en el $2013^{3}$ y luego aparecidos impresos en abril de 2015 (Álvarez del Castillo, 2015). En los trabajos mencionados, se cuestionaba ya el vínculo de Caruso con una institución psicoanalítica mexicana, a la luz de los datos descubiertos. El libro de FG se monta en estos trabajos previos para armar una parafernalia textual pretendidamente más científica y sólida, donde el autor incluye elementos nuevos, tales como tratar de establecer tenue pero inequívocamente una relación de complicidad entre los psicoanalistas Armando Suárez y Raúl Páramo -fundadores del CPM en México- con Caruso a propósito de un supuesto pasado nazi, y se insinúa una especie de pacto de silencio entre ellos sobre dicho pasado.

En el texto de Alejandra de la Garza que inicia el libro de FG, se sitúa el trabajo en un eje incuestionablemente institucional, algo que aparece casi espontáneamente en el proceso emprendido para hacer la historia del CPM -que ella presidía hasta el 2015-. La autora coloca a FG como un agente fundamental en lo que considera una tarea 
dura, compleja y cargada de sentido; dice de la Garza: "es una mirada sobre el affaire Caruso" (p. 22), con lo cual se categorizan de entrada los hechos que dieron lugar al libro como un affaire. Al utilizar ese término, se coagula lo aún no leído sobre Caruso como una materia sospechosa, pero si se revisa el diccionario, se verá que ese término también significa "cuidado, deber, negocio, ocupación, cuestión, necesidad, pleito, proceso, discusión, riña, duelo o combate" (Alcalá-Zamora, 1966, p. 49). En ese sentido, es interesante que, al terminar la lectura del libro, lo que parece quedar claro es que el bautizado affaire Caruso es algo que no que solamente tiene que ver con sospechas sobre la vida de un sujeto histórico y situado en las complejas coordenadas de sus circunstancias, sino también con otras acepciones del término: se percibe una necesidad institucional de hacer deslindes, y se adivinan pleitos y discusiones no explicitados, duelos no terminados y combates a muerte entre quienes quedan de uno u otro lado luego de hacer dichos deslindes. ${ }^{4}$

Quien comienza a leer el libro se ve sometido a una intensa preparación de la mirada a través del tono con el cual se califica el contenido que se encontrará más adelante, antes de que se enuncien con claridad los hechos que motivaron la confección de este texto múltiple. Se habla de "hechos graves", de "un asunto" delicado y complejo, de "acontecimientos al límite” (p. 39). Todo esto va predisponiendo una severa

4. Por otra parte, se habla también del asunto, del caso o del tema Caruso en distintas partes del libro. Conviene preguntar: ¿qué es un caso? Diríamos que es un artefacto conceptual producido a partir de ciertos recortes sobre la realidad empírica, es decir, es el resultado de una operación conceptual que hacemos sobre dicha realidad a partir de elementos fragmentarios. Un caso no existe tal cual, sino que lo creamos al unir los puntos de indicios o trozos dispersos, tanto en el tiempo como en el espacio, lo cual nos permite luego hablar acerca de lo que queremos mostrar.Y eso es lo que hace FG en su libro: construye un caso desde una mirada particular sobre un episodio específico en la vida de lgor A. Caruso a partir de la producción de ciertos datos. Produce así un affaire cargado de sospechas $y$, al mismo tiempo, revelador de algo. ¿De qué?, o más bien, ¿qué quiere mostrarnos al construir el autor del libro este affaire Caruso? 
postura en el lector, a quien se le demanda colocarse en el lugar de juez (sin decirlo abiertamente) frente al material que será presentado. No es sino hasta las páginas 30-31 que se describen los hechos que motivan el libro, y esto se hace así: "Caruso trabajó en el hospital Am Spiegelgrund de Viena, en el pabellón de niños, en donde realizó evaluaciones psicológicas acerca del estado mental de algunos de ellos. En dicho hospital, los superiores de Caruso, a su vez, evaluaban dichos reportes para determinar si practicarían o no la eutanasia”.

Es decir, Caruso - a la edad de veintiocho años y durante ocho meses- hizo evaluaciones psicológicas de algunos niños internos en ese hospital, las cuales eran utilizadas por sus superiores para determinar si dichos niños eran o no sujetos de eutanasia, la cual fue efectivamente practicada en algunos de los casos como parte del programa de limpieza racial de los nazis. O sea que, al mismo tiempo que se acusa a Caruso de participar en la maquinaria del proyecto de eutanasia nazi, se reconoce que este entró a trabajar ahí ignorando dicho proyecto y que, además, no evaluaba a todos los niños y no tenía un puesto de decisión, por lo que no estaba en sus manos tampoco la de matarlos. A pesar de eso, es a partir de esos hechos que se argumentan las razones de una indagación: "Dadas las relaciones entre el CPM y la Red de Círculos de Psicología Profunda, ${ }^{5}$ específicamente con Igor A. Caruso, el asunto amerita una aclaración" (p. 30). Llama la atención esta lógica argumentativa que da por sentada una justificación un tanto, digamos, jalada de los pelos.

El autor del libro actúa aparentemente con una misión -tan encargada como asumida-, que es formulada como "interrogar la novela institucional a fondo" (pp. 27-28). Aquí surgen varias preguntas: ¿de cuál novela institucional se trata?, ¿de cuál institución?, ¿quién participa de la produc- 
ción de esa novela y de esa institución?, ¿quién solicita esa interrogación y para qué? No se buscan las respuestas más obvias: la novela la producen los miembros, y la institución es el CPM, que también es quien pide que sea interrogada. Más bien, preguntamos acerca de cómo se entiende la llamada novela institucional y cómo se piensa la institución, ya que uno de los signos de nuestros tiempos líquidos (Bauman, 2002), según algunos científicos sociales, es la pérdida de sentido que han implicado las transformaciones de los vínculos sociales y que han producido un generalizado descrédito de las instituciones, así como una desconfianza e inconformidad subjetiva con estas, que va de la mano con la falta de compromiso con los propósitos de las instituciones.

Esto se vincula con la llamada crisis de las identidades (Dubar, 2002), derivada del hecho de que ya no se logra articular un sentido de pertenencia en relación con las instituciones donde se trabaja, estudia o hace activismo político o religioso. Las iglesias, los partidos políticos, las instituciones que organizan las elecciones en los regímenes democráticos, las escuelas y las universidades, las empresas, han perdido credibilidad, y quienes forman parte de ellas ya no se identifican con sus misiones ni con sus procedimientos $u$ objetivos. Hay ahora, sobre todo, una relación pragmática de corto plazo de los sujetos con las instituciones con las que se vinculan. Es decir, no significan ya nada fundamental para quienes las componen.

Preguntamos: ¿el CPM del 2015 está exento de estos rasgos? Es decir, ¿de qué institución se habla en este libro? Podría aventurarse que se habla de un CPM que corresponde a sus primeros tiempos, en los años setenta, cuando era otro el significado de estas agrupaciones, las identidades eran sólidas y, para los sujetos involucrados, se ponía en juego mucho más que ahora. Es decir, se trata del escenario de la experiencia personal del autor del libro, pero no del 
escenario en donde se sitúan los miembros y los aprendices en la segunda década del siglo XXI.

Siguen las preguntas: ¿los miembros del CPM actuales se ven reflejados en el drama de una novela institucional que parece levantarse sobre un paradigma identitario y un sentido institucional hoy inexistentes? ¿Todavía se sienten vinculados por lazos afectivos tan fuertes y significativos con una institución que también es distinta de la fundada en los años setenta? ¿Tienen estos sujetos respuestas emocionales como aquellas a las que se alude en el libro -horror ante lo visto, culpa por lo que otros hicieron, desgarramiento identitario-?

Al plantear esto, ¿no estamos más ante un intento de fabular retrospectivamente una imaginada identidad colectiva que ante su cuestionamiento? ¿O se trata, más simplemente, de un ajuste de cuentas generacional? Asimismo, es posible preguntarse si no hay en este esfuerzo también una intención performativa, es decir, la intención de producir algo, de recuperar (o resucitar) algo, de inocular un nuevo aliento en una institución que se extingue, a través de una dramatización artificial de una novela inventada, con cierto parecido a lo que Hobsbawm llama las tradiciones inventadas (Hobsbawm y Ranger, 1984). ${ }^{6}$

Se señala en el libro que la invisibilidad del paso de Caruso por el hospital nazi funcionó para el CPM, "pero no para el contexto austriaco" (p. 30), y se afirma que nunca se preguntó a Páramo y a Suárez sobre ello, lo cual indica "que doblemente se evitó el tema" (p. 30). ¿No tendrá que ver esto con que el contexto vienés no es el contexto del CPM, y que, por lo tanto, ciertas preguntas no tenían espacio para

6. "Prácticas normalmente conducidas por reglas tácitamente aceptadas, y de un ritual o una naturaleza simbólica que busca inculcar ciertos valores y normas de comportamiento por repetición, que automáticamente implica continuidad con el pasado. De hecho, en la medida de lo posible, normalmente se busca establecer continuidad con un pasado histórico deseable" (Hobsbawm y Ranger, I 984, p. I). 
ser formuladas? Es decir, ¿cuál es el contexto que legitima afirmar la gravedad de ese episodio en la vida de Caruso, que lo hace relevante para una institución psicoanalítica mexicana del siglo XXI?

Se explica a partir del contexto que los hijos de los nazis y hasta los nietos de la generación de ciudadanos alemanes no nazis que vivieron el nazismo se pregunten acerca de su genealogía y la participación de sus ancestros en los crímenes cometidos. Ese contexto no es el del CPM, por más que haya un vínculo (ni siquiera directo u orgánico) entre Caruso (que no era nazi), los fundadores del CPM (aunque fueran sus pupilos) y la institución actual.

Ahora bien, se afirma en el libro que el paso de Caruso por el hospital Am Spiegelgrund puede pensarse a partir del relato de Poe de La carta robada. Afirmar esto es construir un relato sobre el CPM a partir de algo que, estando a la vista de todos, no fue notado ni, por lo tanto, interrogado. Sin embargo, no era, pues, un secreto. Y aquí una pregunta: ¿darle a algo el estatus de carta robada no significa construir un acontecimiento a posteriori para hacerlo coincidir con la conclusión que se quiere sacar del relato que se construye? Es decir: primero se afirma que Caruso fue un ser malvado disfrazado de virtuoso, que colaboró con los nazis, y luego se da marcha atrás, no buscando indicios para apoyar la afirmación, sino haciendo un trabajo activo para fabricar indicios a partir de cuestiones azarosas que en realidad no indican nada más allá (tales como un cuñado vinculado con los nazis, la dificultad en encontrar trabajo, el ser aristócrata), pero que si son tratados como prueba de algo, producen la ilusión narrativa buscada. Este proceder se parece peligrosamente a la lógica del delirio.

La construcción del caso Caruso parece basarse en un silogismo extraño: en el hospital Am Spiegelgrund se cometían crímenes, y Caruso trabajó en ese hospital, por lo tanto, Caruso cometía crímenes, pero, además, mentía, escondió su 
participación con los nazis en esos crímenes. Y encima, tuvo el atrevimiento de hacerse psicoanalista a pesar de haber sido criminal. Aquí otra premisa no explícita: hay que ser intachable para ser psicoanalista, lo cual incluye no mentir.

El argumento central del libro (que no es muy sólido ni claro) es que descubrir que Caruso colaboró con los nazis es un hecho grave para el CPM, sus fundadores y demás involucrados. La hipótesis central, no explicitada, es que si Caruso fue un colaborador del régimen nazi, eso tuvo efectos perniciosos en la historia del CPM. Es decir, la marca del mal estuvo en el origen de esta institución y ha permanecido ahí hasta ahora.

Para sostener su hipótesis, lo primero que hace FG es buscar información para contar con pruebas de la colaboración de Caruso con el régimen nazi. Lo segundo es tratar de mostrar que esa información no fue tomada en cuenta por los fundadores del CPM (no queda claro por qué), quienes quedan del lado de la frontera de los marcados por el mal, y que eso produjo efectos institucionales graves que implican tanto a dichos fundadores como a las generaciones siguientes. No se explicita en qué consisten esos efectos.

Además, las pruebas que se presentan sobre la participación de Caruso en los hospitales nazis son secundarias y no contundentes, esto es, lo presuntamente recogido por List, textos de periódicos o revistas, así como trozos de entrevistas realizadas por otros y por el autor del libro. ${ }^{7}$ Puede decirse que no hay en el texto pruebas que sostengan con suficiente solidez las afirmaciones que el autor hace: los datos que se presentan se refieren al desempeño de Caruso como psicólogo en dos hospitales vieneses de la época nazi y algunos

7. Al respecto, llama la atención una entrevista hecha a la hija de Caruso, quien habló con FG sin saber cuál era el objetivo de la investigación y que, cuando lo supo, pidió que no se publicara la información proporcionada. ¿Qué esperaba el autor al entrevistar a esta persona con la intención de demostrar que su padre fue un asesino?, ¿cómo es que, al hacer el encuadre de esa entrevista, no se explicaron los objetivos? 
otros datos relativos a su familia y sus relaciones profesionales, pero no son suficientes para sostener los supuestos que se quieren establecer, y que son los siguientes:

1) Que Caruso fue un colaborador consciente con el régimen de eutanasia nazi;

2) Que fue asesino de niños;

3) Que en la vida de Caruso fueron factores negativos determinantes los siguientes: su origen (aristócrata ruso), sus relaciones familiares (matrimonio, concuño y otros), su formación religiosa (catolicismo jesuita) o sus vínculos profesionales (colegas);

4) Que dichos factores intervinieron en la decisión de Caruso de trabajar en dos instituciones vienesas durante el régimen nazi;

5) Que las actividades mencionadas impactaron negativamente en el desempeño de Caruso como psicoanalista o como formador de analistas;

6) Que pueden establecerse con claridad efectos de la vida personal de Caruso en las trayectorias de los fundadores del CPM (particularmente en Suárez y en Páramo), y en la institución como tal;

7) Que la información relativa a la vida de Caruso durante la ocupación nazi en Austria en la Segunda Guerra mundial es un factor explicativo de por lo menos algunos de los conflictos que se han dado en el seno del CPM, o entre esta institución y otras.

Parecería que la retórica del drama pretende suplir en este libro la falta de pruebas. Un ejemplo: en la página 55 se cita a List, quien dice: "leí en un texto -me refiero a los citados dictámenes- que, de manera terrible, era 'cercano a las víctimas”. ¿Qué querrá transmitir FG al citar esto, sin decirle a quien lee ni siquiera el contenido de ese texto? ¿Tiene el lector que asumir que ese texto era realmente terrible e imaginar los porqués? El libro habla de datos duros, pero 
en realidad ni son datos ni son duros: ${ }^{8}$ se trata de conjeturas y conclusiones a partir de pruebas que no son presentadas a los lectores. No es suficiente con decir que Frau List sí tiene pruebas: habría que presentarlas.

Por cierto, las pretendidas evidencias que se presentan en el capítulo cuatro del libro acerca de los diagnósticos realizados por Caruso que, supuestamente, llevaron a catorce niños a la muerte (pp. 120 y ss.) no son de ninguna manera contundentes. Se presentan trozos de algunos de los diagnósticos hechos por Caruso, pero no se da prueba alguna de que haya una línea directa entre dichos diagnósticos y la muerte de esos niños; además, antes nos había dicho ya el autor que los diagnósticos que hacía Caruso pasaban después a sus superiores, quienes decidían sobre la suerte de esos niños. Más adelante dice el autor: "estos diagnósticos... se convertían en condiciones necesarias[,] pero no suficientes para acelerar la muerte” (p. 127). Lo más que podemos decir es que las frías descripciones de los niños hechas por Caruso resultarían poco empáticas y políticamente incorrectas en el contexto actual, pero sin duda eran muy acordes con el contexto en el que él vivía y trabajaba. De hecho, más adelante (p. 129), FG dice: "faltan elementos para hacerse una idea cabal de cómo los leían [los diagnósticos] los responsables de matar a los niños. Y por qué, en algunos casos, diferían el desenlace".

Por otro lado, el capítulo cuatro muestra un empeño por inclinar las cosas hacia un juicio negativo sobre Caruso, cuando se dan datos que bien podrían inclinarlo hacia el

8. FG dice tener datos duros como pruebas, pero parece ignorar que esta expresión no hace referencia a la gravedad de los datos, sino al tipo de estos, es decir, a los datos numéricos que se rigen por técnicas estadísticas, en oposición a los datos blandos, que son datos no numéricos o cualitativos (como, por ejemplo, notas de campo, fotos, transcripción de entrevistas, documentos oficiales y personales, diarios, películas, etc.), esto es, datos difícilmente manejables mediante procedimientos estadísticos. Siguiendo esto, en el libro de FG no hay ningún dato duro, sino solamente algunos pocos datos blandos. 
otro polo. Así, cuando se dice: "Caruso [...] se acoplaba mal a las normas dispuestas por las instituciones de Am Spiegelgrund, pero no porque estuviera en desacuerdo [...] más bien parece lo contrario [...] se esforzaba por complacer a los médicos" (p. 130), ¿no se podría también interpretar como señal de resistencia ese mal acoplamiento? Parece preferirse interpretar lo contrario, para confirmar lo que se quiere sostener: "No hay indicio de que alguna vez Caruso haya criticado o cuestionado su actividad de dictaminador" (p. 132) es una afirmación que no quiere decir que sí haya indicios de lo contrario, incluso, se agrega un poco más abajo en la misma página: "es probable que no se haya sentido muy cómodo". Otra muestra: "[no hay] ninguna señal de que Caruso tenía simpatía especial por el régimen, pero tampoco hay señal de que él haya actuado de otra manera que conforme al sistema" (pp. 132-133). Queda poco claro entonces qué quiere decir el autor.

Pero hay que tener cuidado, porque FG advierte que alegar que no se presentan suficientes pruebas podría ser una muestra de que quien lo dice simpatiza también con los nazis. No hay salida para quien pueda aspirar a un verdadero rigor en la investigación realizada, es decir, la existencia de un argumento compuesto por afirmaciones claras y explícitas, además de debidamente sustentadas con pruebas precisas.

A pesar de ello, y asumiendo el riesgo de ser acusados de perversos y criptonazis, es posible afirmar que lo que se presenta como pruebas no alcanza para sostener las afirmaciones que se hacen; además, la lógica que está detrás del argumento fabricado es muy cuestionable. Se parte de una premisa falaz que nunca llega a sustentarse sólidamente.

De pronto, el lector parece estar frente a un delirio perfecto donde todo parece encajar con el presupuesto básico: que Caruso era esencialmente malvado. El libro es un juicio acerca de la calidad moral de Caruso, basado en valores no explicitados. En dicho juicio hay elementos del discurso 
de la corrección política más común en nuestros días, pero también hay prejuicios ideológicos jacobinos y clasistas respecto de Caruso (se infieren defectos personales a partir de su origen nacional, familiar, de clase y religioso), que se pretenden poner en relación de determinación directa (si bien con una lógica muy problemática y sin explicitarse claramente) con las actividades que Caruso desempeñó en los dos hospitales donde trabajó y, sobre todo, con su calidad humana y como posterior psicoanalista.

La insistencia en estas afirmaciones sin sostén hace que sea elemental preguntarse, a pesar de que el autor tiene el atrevimiento de decir a los lectores que no deberíamos hacerlo (p. 59): ¿habría de verdad que creer -es decir, con fe- en que no hay nada más detrás del objetivo enunciado que condujo a escribir este libro? ¿Se quiere solamente, como se dice en la primera hoja, "dar cuenta de lo que sucede en una institución psicoanalítica cuando en esta irrumpe algo del orden de lo suprimido" (p. 15)? Podríamos decir que el objetivo no explícito del libro es mostrar (¿desenmascarar?) a Igor A. Caruso como colaborador nazi y asesino y a sus seguidores como sus cómplices, y provocar con ello reacciones institucionales ${ }^{9}$ a partir de un marco teórico que combina dificultosamente el psicoanálisis, el análisis institucional y la historia. ${ }^{10}$

FG dice que su objetivo es hacer historia, sociología y reflexión psicoanalítica, en un proyecto más amplio de la

9. Un par de meses después de la aparición del libro que se reseña, se conocen algunas reacciones institucionales, tales como que se retiró la membresía del CPM a Rodolfo Álvarez del Castillo por su postura frente al tema (Álvarez del Castillo, 2015), la expulsión de algunos miembros del grupo del CPM de Cuernavaca y la renuncia de Alejandra de la Garza a la presidencia del CPM, sólo por mencionar algunas relacionadas directamente con el tema de este libro.

10. En cuanto a la historia, hay en el autor una posición ambigua, ya que en algunas partes habla de sí mismo como sólo un aprendiz de historiador, pero en otras habla de su intención de historiar, de hacer la historia del CPM. La verdad es que no es claro cómo entiende FG tal tarea, porque lo que construye no parece propiamente un relato histórico, sino una combinación de ficción y de novela neurótica institucional. 
reconstrucción de la memoria de la institución. Reconstruir la memoria, ¿desde qué lugar y con qué fin? Además, nos preguntamos: ¿cuál es el espíritu que alienta dicha reconstrucción histórica: el espíritu crítico, la búsqueda del saber, la revelación de una verdad?, o, como se decía antes, ¿más bien se produce un relato tipo examen de conciencia institucional que cubre el deseo de un ajuste o un llamado a cuentas, de una exhibición de vergüenzas, una denuncia, un juicio con veredicto final?

A reserva de que cualquiera o varias de estas preguntas puedan conducir a una respuesta certera, también parece bastante evidente que en la construcción de este trabajo están en juego otras cuestiones no explicitadas y vinculadas con la subjetividad. Por ejemplo, se adivina que hay ahí algo psicoanalítico relacionado con la figura del padre. Un padre que, aunque distante y velado, fue central, y que, después de haber sido adorado, se revela como siniestro y, en esa revelación, pone en evidencia la larga ceguera del hijo. Esa ceguera produce entonces vergüenza y culpa, con las consiguientes ganas de exculparse y redimirse. En ese sentido, vemos ahí un primer objetivo: criticar y aniquilar al padre desmitificado.

FG no solamente juzga y designa a Igor A. Caruso confusamente como cercano al nazismo en este libro, sino que prácticamente lo denuncia como asesino al afirmar que participó en la eutanasia de niños, es decir, el autor parece querer demoler al personaje, su prestigio y lo que de él quede en la memoria institucional y en la de algunos de quienes lo conocieron, trabajaron con él, leyeron y estudiaron su obra. Este objetivo se cumple a través de un alarido cargado de acusaciones públicas. Siguiendo a Rabaté (2013): no es solamente una crítica, sino un crimen.

¿El viejo asunto del asesinato del padre? Algo hay de eso, pero agravado por una desilusión insoportable, lo cual se adivina en la enorme nostalgia por el padre puro y enorme 
que, por filiación, convierte al hijo en un ser maravilloso y soberbio -porque además este cree saber quién es su padre-. En este punto, viene a cuento lo que Paul Auster formula después de la muerte de su padre en La invención de la soledad (1994), cuando se pregunta, luego de afanarse en una búsqueda de rastros que le permitieran conocer la verdad sobre su padre, qué es lo que ha estado haciendo al indagar exhaustivamente las fotografías y los objetos personales que le pertenecieron en vida:

Tenía la impresión de que [sus cosas] podrían ofrecerme una información que yo no poseía, revelarme una verdad hasta entonces secreta,y estudié cada una de ellas con atención, fijándome en los más mínimos detalles, la sombra más insignificante, hasta que todas las imágenes se convirtieron en una parte de mí mismo. No quería que nada se me escapara [...]. [Se me fue revelando en mi búsqueda] una imperiosa y desconcertante fuerza de contradicción. Ahora comprendo que [en una vida] cada hecho es invalidado por el siguiente, que cada idea engendra una idea equivalente y opuesta. Es imposible decir algo sin reservas [sobre mi padre]: era bueno o malo, era esto o aquello. Todas las contradicciones son ciertas (pp. 23-24).

Auster (1994) logra un doble descubrimiento: que, finalmente, "uno no deja de ansiar el amor de su padre, ni siquiera cuando es adulto" (p. 31); y que es imposible entrar en la soledad de otro. Por eso afirma: "Sólo podemos conocer un poco a otro ser humano, si es que esto es posible, en la medida en que él se quiera dar a conocer" (p. 32).

FG parece estar ofendido y enojado porque Caruso no le dio a conocer sus actividades mientras duró el régimen nazi en Austria, y en esa medida, no solamente se avergüenza de haber buscado el amor de ese padre que fue Caruso, sino que este le muestra su ceguera al revelarse como un otro lejano e impenetrable. Ese padre criticado y asesinado es el que está detrás del mito que justifica la nostalgia con- 
temporánea por la autoridad disuelta en la modernidad líquida: la autoridad fragmentada y debilitada, distribuida en mil lugares virtuales y móviles, que ocasiona que ya no se pueda creer en quienes dicen ser la autoridad.

De ahí el impulso iconoclasta y el juego de espejos presentes en el libro de FG, donde hay reflejos de los rostros de Edipo, de Ulises, de Moisés y de quien escribe el libro, quien dice querer "dar cuenta de una identidad institucional que no se consideraba herida hasta ahora" (p. 23), una identidad que describe como "satisfecha, sin fisuras y henchida de espíritu crítico” (p. 23). ¿FG es entonces el héroe que inflige esa herida mortal al CPM que parece considerar necesaria? En todo caso, ¿necesaria para quién o para qué?

En la misma línea de pensar la figura del padre mítico, pero también en relación con las riñas y rivalidades entre los grupos de psicoanalistas, está el reciente libro de Recalcati (2015), titulado El complejo de Telémaco, en el que, para pensar la autoridad paterna en nuestros días, el autor recurre al mito del hijo de Ulises que está siempre a la espera de que regrese el padre y restaure el orden en su casa, y los rescate a él y a su madre de los invasores. ${ }^{11}$

Telémaco mira obsesivamente al mar, al punto por el que desapareció la embarcación de su padre; mira el mar con la ilusión de ver a Ulises, pero también mira con la esperanza de que el mar le traiga un objeto, un trozo de algo, un mensaje que lo oriente, que le ayude a entender cuál es su situación, a entender el presente y a vislumbrar el futuro (Soler, 2015).

Se trataría, pues, no solamente de querer matar al padre que no supo sostenerse en su grandeza y su pureza, sino de

I I. Por cierto, FG habla metafóricamente de Caruso como la Gorgona (p. 25) y ahí cabe la pregunta: isignifica eso que quien devela su pasado es Ulises, el valeroso que enfrenta la cara del terror? He ahí una manera en que el otro denostado convierte a quien lo denuncia, por contraste, en un ser superior moralmente, en alguien más fuerte que el horror mismo, aunque es posible que no sea Ulises, sino más bien Telémaco, quien está detrás del texto. 
exhibirlo y denostarlo en su miseria humana, trazando una frontera moral entre él y un nosotros no explicitado pero que construye un lugar de pureza desde donde se le acusa. Así, este trabajo cumple también la función de fijar lugares, posiciones correctas y fronteras morales entre distintos contingentes construidos por el autor.

Particularmente interesante es la frontera que levanta el autor entre su trabajo y el que realizan quienes hacen "objeciones sociológicas y metodológicas, o simples adjetivaciones [...] [que son] las formas en que algunos psicoanalistas reaccionan a las averiguaciones y revelaciones de corte histórico-ético" (p. 34). Señala que "[sus críticas] no tienen ninguna ventaja sobre cualquier mortal, sino que incluso en varias reacciones se puede detectar un uso de las herramientas psicoanalíticas como filtros y barreras para no tener que enfrentarse a lo que surgió sin pedir permiso" (p. 34).

Esto último parece la construcción de lo que coloquialmente se llama curarse en salud: antes de que alguien se atreva a cuestionar lo que uno plantea, se descalifican de antemano los cuestionamientos y objeciones que, aun si se usan herramientas psicoanalíticas para ellos, serán para el criticado inobjetablemente malintencionadas o carentes de sustento. Así, en la página 59 del libro, se desmontan por adelantado las críticas que pudieran cuestionar la investigación realizada por el autor del libro, o que la consideren sospechosa de "negras intenciones, idealizaciones, ajuste de cuentas, entre otras" (p. 59).

Es decir: el autor tiene la audacia de adelantarse a las críticas que al parecer él mismo avizora, y de ir callándolas antes que siquiera se formulen. Esto es curioso porque parecería que entonces él sabe que es posible preguntarse acerca de las intenciones, las idealizaciones, los ajustes de cuentas, entre otras cosas, pero no los explicita. Al contrario: plantea objetivos aparentemente asépticos, libres de toda contaminación subjetiva, aunque reconoce estar implicado 
sin decir cómo, en qué grado y, sobre todo, cuáles han sido las consecuencias de dicha implicación en la construcción de su objeto y en el procedimiento empleado para argumentar lo que afirma con su trabajo.

La lectura del libro de FG lleva a pensar acerca de las ventajas que tiene la literatura (la ficción) sobre los libros serios y académicos. Finalmente, es en la literatura donde podemos apreciar la construcción de personajes densos, que nos deja asomarnos a la complejidad de los humanos: sus miserias y grandezas, sus heroísmos y sus errores, sus tropiezos, yerros, malas decisiones, pero, sobre todo, su opacidad y sus fracturas internas. En ese sentido, la literatura nos deja saber más sobre lo que somos que los relatos como el que construye FG, que pretende hablar de personas reales sin contradicciones ni fisuras, de hombres de una pieza: malo o bueno; nazi, católico o psicoanalista; siniestro o amable.

Sin embargo, la ficción a veces también sirve de coartada. Fue muy interesante descubrir que FG leyó la más reciente novela de Javier Marías (2014) desde un ángulo que parece confirmarle una perspectiva que, desde nuestro punto de vista, es más bien antagónica respecto de la utilizada por él mismo para hablar de Caruso. ${ }^{12}$ El libro de Marías, desde el territorio de la ficción, habla de las atrocidades que tuvieron lugar en la Guerra Civil española; el de FG, desde una mirada pretendidamente histórica, habla de las atrocidades del nazismo.

En el primero, se construye un relato en el cual poco a poco se va revelando que todos los personajes tienen un lado oscuro, un pecado cometido: un chantaje, una traición, una falta de lealtad, una infidelidad. En el segundo, se denuesta a un psicoanalista anteriormente considerado como inta- 
chable. En ambos libros se trata el prestigio de sujetos que esconden en su pasado una mancha que, al revelarse, habla de la verdadera naturaleza maligna del sujeto, del engaño hacia quienes lo creyeron bueno y honesto, y que una vez revelada la verdad, merece toda la ira de los justos. Sin embargo, el libro de Marías muestra que así somos los humanos; el de González parece suponer que hay naturalezas puras o esencialmente buenas y malas.

Curiosamente, el libro de FG da la impresión de apegarse menos a lo que sabemos de lo que somos. Por otra parte, ¿cómo es que un psicoanalista podría desconocer lo que se sabe desde siempre acerca de la naturaleza humana, y que los grandes de la literatura y la poesía han dicho de mil maneras? Ahí está lo dicho, por ejemplo, por Joseph Conrad: la creencia en algún tipo de maldad sobrenatural no es necesaria. Los hombres por sí solos ya son capaces de cualquier maldad; y por Chesterton, cuando según la tradición le preguntaron si era un demonio: soy un hombre. Y, por lo tanto, tengo dentro de mí todos los demonios.

W. H. Auden también sabía esto cuando, se dice, señaló: el mal es vulgar y siempre humano, y duerme en nuestra cama y come en nuestra mesa. Lo mismo puede decirse de Freud, quien en el contexto de la inminente Primera Guerra mundial discutió la idea de que las malas inclinaciones del hombre le son desarraigadas por la educación y la cultura para ser sustituidas por inclinaciones a hacer el bien:

En realidad, no hay “desarraigo" alguno de la maldad. La investigación psicológica -en el sentido más estricto, la psicoanalítica- muestra más bien que la esencia más profunda del hombre consiste en mociones pulsionales; de naturaleza elemental, ellas son del mismo tipo en todos los hombres y tienen por meta la satisfacción de ciertas necesidades originarias. En sí, estas mociones pulsionales no son ni buenas ni malas. Las clasificamos así, a ellas y a sus exteriorizaciones, de acuerdo con la relación que mantengan con las necesidades y las exigencias de la comunidad humana. Ha de 
concederse que todas las mociones que la sociedad proscribe por malas -escojamos como representativas las mociones egoístas y las crueles- se cuentan entre estas primitivas (Freud, 1998, pp. 282-283).

¿De dónde sale ahora, en este enjuiciamiento a Caruso, la necesidad de hacer de Torquemada frente a las manifestaciones del viejo conocido que habita en los humanos? ¿Por qué este personaje estaría a salvo del mal y sus demonios?, ¿cómo pudo trabajar Caruso como psicoanalista con ese pasado sin atragantarse?, es decir, ¿solamente los espíritus puros pueden trabajar como psicoanalistas sin atragantarse?

El libro responde a la convicción del autor de que, si bien los miembros actuales del CPM no son culpables ni responsables de los crímenes cometidos por sus fundadores, de alguna manera serían responsables de la propia mirada. ¿Qué es lo que se quiere decir con eso? ¿Se trata de no cerrar los ojos o de cargar la mirada de un contenido que juzga lo que ve? ¿Y qué pasa cuando al mirar de esa manera percibimos lo que se llama el horror? ¿No será más bien que en ese momento lo visto toma categoría de horror porque lo que vemos es la caída de las figuras idealizadas? ¿Es eso el horror, lo siniestro u ominoso? ¿Y a quién incluye ese nosotros de la mirada colectiva? ¿A todos los analistas, a toda la institución, a sus fundadores, a quienes creyeron en ellos, a quienes se han formado ahí, a quienes no son como ese, o a quienes intervienen en los distintos textos que componen este libro y en sus presentaciones y promoción?

En relación con el punto anterior, se lee en la página 25: "el lugar del analista se sostiene en una ética de la verdad que debería estar por encima de los intereses nacionales y de la pretendida pureza identitaria”. La afirmación es contundente, pero nada clara. ¿Es realmente así? ¿De eso se trata este libro, de construir un argumento desde la ética de la verdad? Por una parte, tenemos la impresión de que 
el lugar del analista depende en teoría de una ética de la verdad, mientras que, en la humanísima realidad, dicho lugar depende más de la creencia de que se posee la verdad; a partir de ahí, se fabrica una identidad gremial que se funda, en buena parte, en una especie de creencia en una superioridad intelectual -compuesta de una improbable habilidad comprensiva y de cualidades de clarividente-, pero sobre todo, en una pretendida superioridad moral. ${ }^{13}$

El libro sobre Caruso tiene, por otra parte, un estilo bastante reconocible. En distintos puntos se hacen afirmaciones cuyo fundamento no se explicita, y se formulan preguntas que se dejan abiertas y cuyas respuestas no son obvias, aunque se sugieren sin enunciarlas. Lo que sobre todo se sugiere es que en lo que no se acaba de decir hay un sobreentendido que se convierte en lo que permite distinguir a quien entiende de quien se niega a entender. Si no se entiende-lo no dicho, lo no explicitado, lo no enunciado-, entonces el lector está bajo el efecto de la negación, la cual confirmaría que eso no dicho tiene el valor de la verdad; lógica circular y compacta que atrapa a quien muestra desconcierto por las enormes afirmaciones sin respaldo que encontramos a lo largo del texto de FG.

En el plano del lenguaje utilizado en el libro puede decirse que el uso de ciertos términos da un tono particular a la lectura: culpa, responsabilidad, secreto, mecanismos de

13. ¿En qué se fundan, si no, los incontables pleitos y rencillas entre las distintas instituciones analíticas y entre las diferentes facciones que van resultando de ellos? ¿Cuál es el verdadero fondo de las mutuas acusaciones? ¿Qué es lo que quiso decir Freud cuando, al ver el auditorio lleno antes de dar una conferencia en Estados Unidos de América, comentó a Ferenczi que de todos los presentes podría contar con los dedos de una mano a los que realmente podrían ser analistas? ¿Qué quiso decir un analista mexicano cuando afirmó que si no se habla alemán, si no se conoce la cultura germana y si no se ha formado uno con un analista verdadero, no se es realmente analista? ¿Cómo se construyen esas fronteras entre los buenos analistas y aquellos que no merecen serlo, entre los verdaderos y los impostores? ¿No es el dispositivo del llamado análisis didáctico una criba que separa el grano de la paja, como dice el Evangelio, y que ha sido motivo de violentas discusiones y hasta de rupturas institucionales? 
purificación. Se alude a un principio de la transparencia y a la corrección política. Al parecer, el autor se sitúa en lo que Han (2013) llama "la sociedad positiva" (p. 11) de la que dice que no admite ningún sentimiento negativo porque, en su afán de acelerarse y debido a su característico sistema de transparencia, suprime toda negatividad. ¿Qué podría ser lo que se formula como un flagrante delito de silencio?

El discurso del libro de FG es el de la corrección política contemporánea; está lleno de compasión por los discapacitados y los menores, y responde al aliento de un imperativo de transparencia. Por otra parte, el abuso de superlativos hace extenuante la lectura. Está escrito de manera confusa, está plagado de adjetivos y de gerundios, y tiene un exceso de referencias cuya utilidad resulta dudosa la mayor parte de las veces.

Además, este libro parece dialogar con los críticos de otros libros anteriores del mismo autor. Da la impresión de que el caso Caruso, más allá de su construcción e interpretación, es utilizado para contraargumentar a dichos críticos y para mostrar todos los recursos de que dispone para situarse legítimamente como juez de personajes perversos. A lo largo del texto, se recurre a las menciones y citas de tantos autores que da la impresión de que se trata de una especie de ejercicio escolar, de una tesis que parece haberse construido sobre el principio de que mientras más autores se citen, más posibilidades tendrá de ser aceptada por el sínodo examinador.

Uno de los problemas de pensar este libro como un aporte al conocimiento es que no se llega a saber con claridad qué es lo que se puede conocer a través de él sobre el tema tratado. Lo que uno sabe -sin ninguna precisión- al final de la trabajosa lectura es que el campo del trabajo psicoanalítico es extraordinariamente conflictivo, y que dista mucho de estar compuesto por seres mejores que el resto de los humanos. 
Alcalá-Zamora, P. (1966). Diccionario francés-español y españolBibliografía francés. Barcelona: Ramón Sopena.

Álvarez del Castillo, R. (Comp.) (20I5). Psicoanálisis, nazismo, historia e institución: el caso lgorA. Caruso. México:Ediciones Cuadernos Melanie Klein.

Auster, P. (1994). La invención de la soledad. Barcelona: Anagrama.

Bauman, Z. (2002). Modernidad líquida. Buenos Aires: FCE.

Cercas, J. (30 de agosto de 20I5). "Hitler, Isabel II y la nueva política”. El País semanal, p. 8.

Coffey,A., y Atkinson, P. (2003). Encontrar el sentido a los datos cualitativos. Estrategias complementarias de investigación. Antioquia: Universidad de Antioquia.

De Jarcy, X. (20I5). Le Corbusier, un fascisme français. París: Albin Michel.

Dubar, C. (2002). La crisis de las identidades. Barcelona: Bellaterra.

Faye, E. (2009). Heidegger. La introducción del nazismo en la filosofia. Madrid:Akal.

Freud, S. (1998). "De guerra y muerte. Temas de actualidad”, en S. Freud (Aut.), Obras completas, vol. 14 (pp. 282-283). Buenos Aires:Amorrortu.

García Olea, L. (2005). "Las raíces del nazismo en la cultura europea”. Anglogermánica Online. Recuperado de: http://anglogermanica.uv.es:8080/Journal/Viewer. aspx? Year=2005\&ID=garcia.pdf

González Î́niguez, S. ( 1999). “El nazismo de Heidegger”. Revista de la Universidad de Guadalajara, (16), 45-60.

Han, B. C. (20I3). La sociedad de la transparencia. Barcelona: Herder.

Hernández Lomelí, F.(1999).“Carl Gustav Jung y la maraña de malentendidos”. Revista de la Universidad de Guadalajara, (I6), $4 \mathrm{I}-45$.

Hobsbawm, E., y Ranger,T. (Eds.) (1984). The Invention ofTradition. Cambridge: Cambridge University Press. 
Bibliografía | Ibarra, L. (1999). "Carl Gustav Jung y el nacional socialismo”. Revista de la Universidad de Guadalajara, (16), 37-40.

Marías, J. (2014). Así empieza lo malo. Barcelona:Alfaguara.

Orozco,T. (1995). Platonische Gewalt:Gadamers politische Hermeneutik der NS-Zeit. Berlín:Argument Verlag.

Rabaté,J.M.(20I3).“El código DaVinci de Freud.La interpretación como crimen”. Diecisiete, teoría crítica, psicoanálisis, acontecimiento, (2), I23-210.

Recalcati, M. (20I5). El complejo de Telémaco. Barcelona:Anagrama.

Soler, J. (20I5). "Los hijos de Ulises”. El País. Recuperado de: http://elpais.com/elpais/2015/04/24/opinion/I42990I083_52I769.html 